MATEC Web of Conferences 44, 02056 (2016)

DOI: $10.1051 /$ matecconf/20164402056

(c) Owned by the authors, published by EDP Sciences, 2016

\title{
A Novel Motor-Speed-Regulation Method
}

\author{
Zhou Huang ${ }^{1,2}$, Zheng Wang $\mathrm{Xu}^{1,2, a}$ \\ ${ }^{1}$ School of Electrical and Electronic Engineering, Hubei University of Technology, Wuhan, China \\ ${ }^{2}$ Hubei Collaborative Innovation Center for High-efficiency Utilization of Solar Energy, Hubei University of technology, Wuhan, China
}

\begin{abstract}
The traditional doubly-fed motor has less reliability because it needs carbon brushes and sliding rings which are not highly reliable. The brushless doubly-fed machine costs a lot for its framework requires special designing and processing. To overcome the disadvantages of the two kinds of motors, this paper focuses on a novel method of motor speed regulation which is based on rotating feeding. The motor speed changing around its rated speed can be realized based on the method without any carbon brush or sliding ring on the prosaic electrical motors. On the basis of the full controlled thyristor rectifying bridge structure, the basic idea is introduced; the advantages and disadvantages of this method are analyzed. This kind of systems can replace the brushed or brushless double-fed systems. They are very suitable for driving fans or pumps, or power-generating systems with variable speed constant frequency such as wind power or water power generating systems.
\end{abstract}

\section{Introduction}

At present, high voltage motors with high-capacity are widely used. Since the high voltage power transducers with high-capacity are quite expensive, most motors have to act in their rated speed. That will waste a great deal of energy. Some of them even could not work because their rated speed is not suitable in certain condition. For example, some factories supply water with high-capacity motors, and the demand for water varies according to the factory production conditions. When water consumption is stepping down, the water flow can only be regulated by valves because the motor can not regulate its speed. That causes energy waste and water waste. Another example is the drainage and irrigation station. There, low-head water is necessary for water and energy saving in the irrigation working condition, and on the other hand high-head water is beneficial to the rapid waterlogging drainage. If the motor can not regulate its speed, which will result in water wasting and energy wasting in irrigation, and will cause too slow drainage or even close down because the water head is not high enough to overcome the waterlogging pressure.

Since the doubly-fed motor is known, because it has a lot of advantages, such as, its speed can be regulated around its rated speed, a high-capacity motor can be controlled by a small-capacity transducer, the energy can be transmitted by a two-way duplex, it is very suitable for driving fans or pumps, or power-generating systems with variable speed constant frequency such as wind power or water power generating. A lot of scholars have been studying the doubly-fed machine and make a large number of achievements, such as improvements on the structure of rotor or stator structure, making a sane choice of transducers and power devices, the design of topology, the closed loop control strategy, vector controlling method, power allocation, reactive power controlling, motor starting, etc [1-5].

The traditional doubly-fed motor has a transducer which is connected to the motor's rotor. The motor speed can be regulated by adjusting the output frequency of the transducer. Because the transducer processes only the slip power, its capacity is usually much smaller than that of the controlled motor. When the motor speed is adjusted around its rated speed, it only demands a transducer with $1 / 2 \sim 1 / 5$ of the motor capacity to realize the control. This kind of speed regulation system has come true in various fields, such as driving fans or pumps, or wind power-generating systems.

However, the traditional doubly-fed motor needs carbon brushes and sliding rings linking output of the transducer to the rotor which degrade the reliability of the system badly. We had to take into consideration the actual conditions for inspection and repair of the carbon brushes and sliding rings. In order to overcome this defect, Hunt broached a new idea about doubly-fed motor without any carbon brush and sliding ring. This kind of motor, named brushless doubly-fed motor, is studied deeply [6-10]. This type of motor is characterized by putting a control winding in the stator together with the power winding. A frequency

${ }^{\mathrm{a} C}$ Corresponding author: xuzw72@163.com

This is an Open Access article distributed under the terms of the Creative Commons Attribution License 4.0, which permits unrestricted use distribution, and reproduction in any medium, provided the original work is properly cited. 
adjustable power is fed to the control winding by a transducer. This type of motor does not only maintain the advantage that the traditional doubly-fed motor needs a small-capacity transducer to regulate speed in a little pond, but also overcome the disadvantage that the traditional doubly-fed motor needs carbon brushes and sliding rings. But the brushless doubly-fed motor has a complicated framework, which is needed for special design and treating. So it can't be used in the normal motors. That is the reason that this kind of system has not been widely used in practice.

\section{The idea of rotating feeding}

Because the two kinds of doubly-fed systems have disadvantages mentioned before, if a new doubly-fed method is found for normal electrical motor, it will have a cheerful prospect. We analyzed the principle of the brushless doubly-fed motor carefully. And we found that there are two suits of stator windings in a brushless doubly-fed motor. The windings are fed by two sinusoidal currents with different frequencies separately. So, there are two rotating magnetic field established in the stator air gap with different speed. Both of them couple with the rotor and exchange energy with it. Then the output frequency of the transducer, which is connected to the controlling winding in the stator, can affect the rotating speed of the rotor.

According to the working principle of electrical motors [11], the motor working state is the interactive result of the rotating magnetic fields in the stator air gap produced by the stator current and the rotor current separately. It has only relationship with the magnetic fields, and it has no relationship with how the fields produced. That is to say, the rotating fields produced by different means have the same effect. If two stator rotating magnetic fields with different frequency can be produced in normal electrical motor which has only one stator winding, the working state in the brushless doubly-fed motor is imitated, and then doubly-fed speed regulation can be realized in the normal motors.

Because there is only one stator winding in the normal electrical motor, a short circuit accident will appear when the power source and the source outputted by the transducer are fed simply parallel to the stator by a hard connection. So the speed regulation can not be realized by that method. In order to solve the problem, we think an idea of rotating feeding. On the basis of rotating the motor on its rating speed by fed a line-frequency power source to it, the line-frequency source is "rotated" with a certain frequency. The motor speed will step upper than the rated speed if the rotating direction of the source is the same of the direction the rotor. Otherwise, the motor speed will step lower than the rated speed. And the variation of the motor speed is proportional to the rotating frequency of the source. The idea can be explained vividly. First, the stator is fed by a line-frequency power source, and the rotor rotates on the rated speed. Second, to imagine we can rotate the motor wholly on the basis of the condition in the first step, then the rotor will rotate on a different speed, and the direction and the quantity of the variation have relationship with the direction and the speed by which we rotate the whole motor. Last, because the stator can not be rotated actually, if the fed source is rotating on a certain frequency then the effect will be the same as rotating the whole motor.

\section{The structure and the voltage waveforms of the example system}

In order to reduce the production cost, we planed to develop the project on the basis of thyristor. The circuit analyzed below is consists of three-phase full controlled rectifying thyristor bridges. The circuit structure is shown in Figure 1. The three-phase AC power is fed to three same transformers. They output 3 three-phase AC powers with same voltage and same phase. The 3 powers are fed to the stator by an inverter consisted of thyristors.

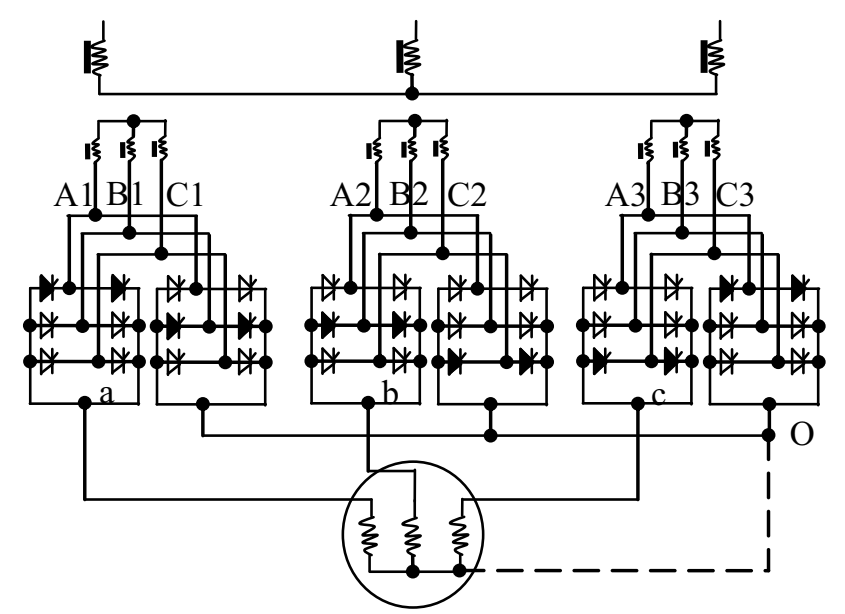

Figure 1. The structure of the example system

In Figure 1, $\mathrm{A} 1 \mathrm{~B} 1 \mathrm{C} 1 、 \mathrm{~A} 2 \mathrm{~B} 2 \mathrm{C} 2 、 \mathrm{~A} 3 \mathrm{~B} 3 \mathrm{C} 3$ are the 3 three-phase $\mathrm{AC}$ powers. The same phases of the three powers (for instance $\mathrm{A} 1 、 \mathrm{~A} 2 、 \mathrm{~A} 3$ ) have same voltage and same phase with each other. Because the three AC powers come from different transformers, the direct connection of different phases causes no short current. The illustration of the connection of the neutral point $(\mathrm{O}$ point) is shown in Figure 2. In the figure, the $\mathrm{B}$ phase of the first transformer, the $\mathrm{C}$ phase of the second transformer and the A phase of the third transformer are connected directly, there is no short current because there is no current loop.

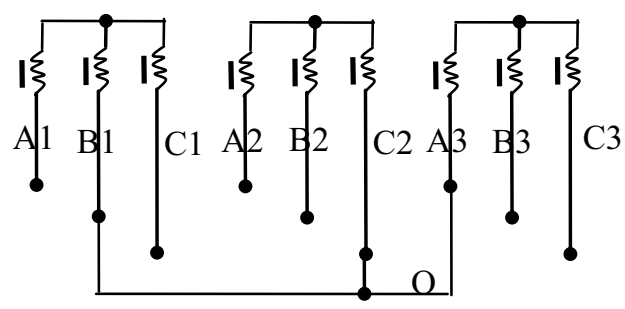

Figure 2. The illustration of the connection of the neutral point 
But the three phase voltage and phase relationships are maintained in $\mathrm{A} 1 \mathrm{~B} 1 \mathrm{C} 1 、 \mathrm{~A} 2 \mathrm{~B} 2 \mathrm{C} 2 、 \mathrm{~A} 3 \mathrm{~B} 3 \mathrm{C} 3$. If misunderstanding will not be caused, the indexes 1, 2, 3 will not be marked below. That is, $\mathrm{A} 1 \mathrm{~B} 1 \mathrm{C} 1 、 \mathrm{~A} 2 \mathrm{~B} 2 \mathrm{C} 2$ 、 $\mathrm{A} 3 \mathrm{~B} 3 \mathrm{C} 3$ are represented by the same as $\mathrm{ABC}$. Their voltage waveforms are shown in Figure 3.

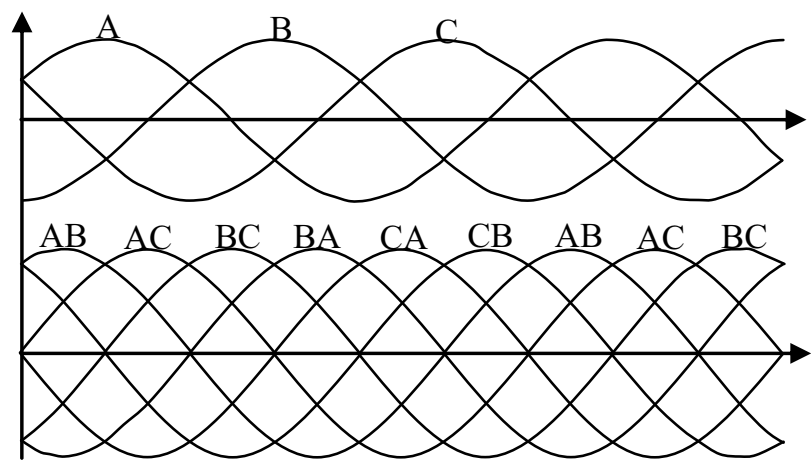

Figure 3. The waveforms of 3 three-phase AC phase voltages and line voltages

\section{The working procedure of the rotating-fed system}

We can see in the Figure 1, if the black thyristors conduct (the two thyristors connected in every phase work half of cycle alternately), and the other thyristors are cut off all the time, then $\mathrm{O}=\mathrm{B} 1=\mathrm{C} 2=\mathrm{A} 3, \mathrm{a}=\mathrm{A} 1, \mathrm{~b}=\mathrm{B} 2$, $\mathrm{c}=\mathrm{C} 3$. Because the neutral point of the motor is also $\mathrm{O}$, the phase voltage on the three stator windings are A1B1, $\mathrm{B} 2 \mathrm{C} 2$ and $\mathrm{C} 3 \mathrm{~A} 3$ separately, or $\mathrm{AB}, \mathrm{BC}$ and $\mathrm{CA}$ (their waveforms are shown in the left side of the moment $t_{1}$ in Figure 4). They form a three phase balance AC power with a frequency of line-frequency. So a rotating magnetic field with synchronous speed will be established in the motor air gap. The motor will work on the rated speed if the state is maintained all the time.

However, at a certain required moment, for example, at the moment $t_{1}$ in Figure 4, if the neutral point is changed from $\mathrm{B} 1=\mathrm{C} 2=\mathrm{A} 3$ to $\mathrm{C} 1=\mathrm{A} 2=\mathrm{B} 3$, that is realized by changing the thyristors connection of the neutral point, then the phase voltages on the motor stator windings change to $\mathrm{AC}, \mathrm{BA}$ and $\mathrm{CB}$ (their waveforms are shown in Figure 4 between the moments $t_{1}$ and $t_{2}$ ). That is equivalent to there is a $60^{\circ}$ phase lag shift appearing in the phase voltages, and that reduce the motor's speed from its rated speed.

If it is necessary, at another moment, for example, at the moment $t_{2}$ in Figure 4, the inputs of the motor a, b and $\mathrm{c}$ are changed to $\mathrm{B} 1, \mathrm{C} 2$ and $\mathrm{A} 3$ by changing the thyristors connection, and the neural point $\mathrm{O}$ is kept, then the phase voltages of the motor are changed to $\mathrm{BC}$, $\mathrm{CA}$ and $\mathrm{AB}$ (their waveforms are shown in Figure after the moment $\mathrm{t}_{2}$ ). There is a $60^{\circ}$ phase lag shift further appearing in the phase voltages.

So there is a $60^{\circ}$ phase lag shift at every time of changing, the phase voltages change back to the original state of $\mathrm{AB}, \mathrm{BC}$ and $\mathrm{CA}$ after six times of changing to finish a whole cycle. If the intervals between two times of changing are equal to each other, represented by $\Delta t$, then the period of a whole cycle can be written as $\mathrm{T}_{2}=6^{*}$ $\Delta \mathrm{t}$. The rotating speed of the rotor can be written as:

$$
n=n_{e} *\left(f_{1}-f_{2}\right) / f_{1}
$$

Here, $n_{e}$ is the rated rotating speed, $f_{1}$ is the line-frequency, and $f_{2}=1 / T_{2}$ is the rotating frequency of the feeding.

If the direction of the changing is changed, for example, at the moment $t_{1}$ in Figure 5, the neutral point $\mathrm{O}$ is not changed and the inputs of the motor $\mathrm{a}, \mathrm{b}$ and $\mathrm{c}$ are changed to $\mathrm{C} 1, \mathrm{~A} 2$ and $\mathrm{B} 3$, then the phase voltages are changed to $\mathrm{CB}, \mathrm{AC}$ and $\mathrm{BA}$ (their waveforms are shown in Figure 5 after the moment $t_{1}$ ). That is equivalent to there is a $60^{\circ}$ phase leading shift appearing in the phase voltages, and that increase the motor's speed from its rated speed. If the intervals between the changing moments are also $\Delta t$, then the rotor speed can be written as:

$$
n=n_{e} *\left(f_{1}+f_{2}\right) / f_{1}
$$

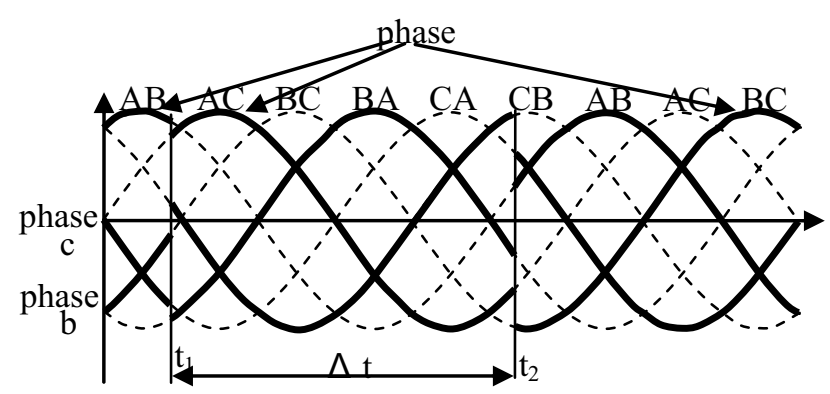

Figure 4. The illustration of rotating-fed

Here, $n_{e}, f_{1}$ and $f_{2}$ have the same meanings as in (1).

According to (1) and (2), the motor's speed can be adjusted upper or lower than the rated speed by the rotating feeding to achieve the same speed regulation results as the doubly-fed motors.

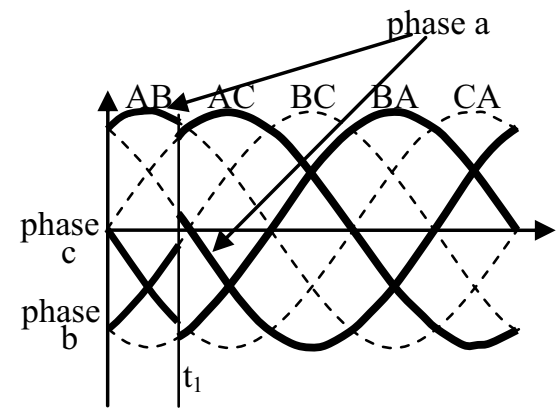

Figure 5. The illustration of rotating-fed with an exceeding rated speed

\section{Conclusions}

In the analyzing before, it is not taken into account that the voltages fed to the motor should be changed together with the frequency. We can realize that by conduct the other side thyristor a certain time after every time of phase current changing to zero. But that causes some problems such as reducing the output voltages, 
degrading the waveforms, producing harmonics. For high-capacity motors, these effects can be reduced by using a multiple structure for the transducer.

However, there still is a problem to bring the method true. Because the inverter consisted of three phase full controlled rectifying bridges is mounted between the power grid and the motor, the whole power that is fed to the motor should pass through the transducer entirely, so the capacity of the transducer should be equal to or even larger than the capacity of the motor. It can not be realized that using a small-capacity transducer to control a high-capacity motor. For this problem, the solving method is in thinking. We prepare to feed two sinusoidal $\mathrm{AC}$ power with different frequencies into the stator windings by a different manner to realize the doubly-fed speed regulation for the normal motors.

\section{Acknowledgment}

This work was supported by the Key Project of Hubei Provincial Science and Technology Department, under grant 2009AA413C. We thank Professor Liu Qun for his researching on the speed regulation of doubly-fed motors.

\section{References}

1. H. Liu, Q. Tang, L. Zhu, D. Zhao, C. Li, L. Shi, power system protection and control system, 24, 79-85 (2014)

2. S. Li, Z. Yang, Z. Liu, S. Sun, power system protection and control system, 4, 8-13(2012)

3. L. Zhan, X. Jin, L. Zhang, Electrical Technology, 1, 130-135 (2012)

4. Y. Li, F. Zhu, X. Zhu, H. Xu, Electrical Technology, 7, 161-166 (2011)

5. M. Tian, C. He, Xi'an University of Science and Technology, 1, 107-111 (2013)

6. Y. Chong, X. Wang, F. Xiong, Y. He, Chinese Society for Electrical Engineering, S1, 203-210 (2013)

7. C. Kan, J. Zhang, G. Chu, B. Ma, Hefei University of Technology (Natural Science), 12, 1436-1440 (2014)

8. L. Han, H. Wang, N. Ma, H. Liu, Electric Machines and Control, 3, 22-29 (2012)

9. S. Gong, X. Yang, L. ji, Electric Power Automation Equipment, 8, 60-65 (2012)

10. R. Zhao, X. Wang, A. Zhang, micro motor, 7, 18-23 (2013)

11. J. Keljik, Electric Motors \& Motor Controls, (2011) 